\title{
PELATIHAN PEMBUATAN MODEL 3D ALAT PERAGA EDUKASI HIDROLOGI BERBASIS AUGMENTED REALITY UNTUK GURU
}

\author{
Budi Arifitama ${ }^{1)}$ \\ ${ }^{1)}$ Program Studi Teknik Informatika, Universitas Trilogi \\ Email : budiarifitama@gmail.com
}

\begin{abstract}
ABSTRAK
Augmented reality pada perkembanganya di Indonesia telah banyak digunakan sebagai media bantu dalam pengajaran di kelas agar pembelajaran menjadi lebih interaktif antara pengajar dan murid. Murid dapat belajar mandiri dengan mengamati alat peraga augmented reality yang dikembangkan tanpa perlu dipandu. Namun sayangnya masih sulitnya pengembangan aplikasi augmented reality, menjadikan belum banyaknya para guru yang dapat mengembangkan aplikasi berbasi augmented reality. Atas dasar permasalahan tersebut, melalui organisasi APSI, dilakukanya kegiatan pengabdian kepada masyarakat dalam bentuk pelatihan pembuatan model 3D berbasis augmented reality yang diikuti oleh perwakilan dari para guru se-Jadebotabek sebanyak 15 Guru. Kegiatan pelatihan dibagi menjadi 3 sesi, yaitu sesi pertama melalui metode ceramah, sesi kedua metode tutorial terpandu dan sesi terakhir dengan latiihan. Hasil dari pelaksanaan pelatihan ini adalah guru mampu membuat aplikasi augmented reality secara mandiri dan mampu membuat alat peraga hidrologi berbasis augmented reality yang dapat digunakan untuk memperkaya pembelajaran di kelas.
\end{abstract}

Kata kunci : Pengabdian Kepada Masyarakat, Augmented Reality, Hidrologi

\begin{abstract}
Augmented reality in Indonesia has been widely used as a media aids in teaching in the classroom, to enhance a better learning interaction between teachers and students. Students can learn independently by observing augmented reality objects that are developed without the need to be guided. Unfortunately developing an augmented reality application takes a lot of effort especially for teachers, there are not many teachers who can develop an augmented reality application. Based on these problems, through the APSI organization, community service activities were carried out in the form of training on making $3 D$ models based on augmented reality which was attended by representatives of 15 teachers from Jadebotabek. The training activities were divided into 3 sessions, namely the first session through the lecture method, the second session the guided tutorial method and the last session with training. The results of the implementation of this training are the teacher is able to make augmented reality applications independently and is able to make augmented reality based hydrological teaching aids that can be used to enrich learning in the classroom.
\end{abstract}

Key words: Community Service, Augmented Reality, Hydrology 


\section{PENDAHULUAN}

Teknologi augmented reality merupakan salah satu inovasi yang dapat menciptakan ilusi digital dimana seolah-olah objek 3 dimensi yang biasa terdapat di dalam dunia digital dapat hadir berinteraksi di dunia nyata (Azuma, 2017). Hadirnya objek digital di dunia nyata memudahkan proses pembelajaran, dimana murid dapat secara langsung berinteraksi, mengamati dan bereksperimen dengan objek tersebut. Hal ini berdampak positif dalam perkembangan pengetahuan murid dalam pengelola informasi. Namun, untuk dapat menghasilkan sebuah produk ajar berbasis augmented reality masih sangat sulit khususnya untuk para guru, dikarenkan teknologi ini masih tergolong baru sehingga masih sedikit pengembang yang dapat menguasai teknologi ini. Padahal, banyak sekali manfaat yang dapat dihasilkan dari teknologi ini seperti alat peraga berbasialat $\mathrm{s}$ augmented reality pada pengenalan tata surya(Arifitama, 2015), alat pembelajaran hidrologi (Syahputra and Arifitama, 2018) dan alat peraga pendidikan lainnya yang tentunya dapat dikembangkan oleh guru dengan ragam mata pelajaran yang dikuasainya. Melalui inisiatif organisasi Asosiasi Pengawas Sekolah Seluruh Indonesia (APSI) menjembatani kegiatan pelatihan pembuatan augmented reality untuk perwakilan guru se-Jabodetabek. Kegiatan pelatihan ini menjadikan tugas dan kewajiban bagi dosen sebagai kegiatan pengabdian kepada masyarakat di samping kewajiban mengajar dan meneliti. Peserta dari kegiatan ini berjumlah 15 guru dengan berbagai latar belakang disiplin keilmuan yang membutuhkan pengetahuan tentang augmted reality dan pembuatan aplikasi augmented reality. Proses hidrologi berbasis augmented reality dipilih sebagai contoh aplikasi alat peraga, dan juga gambaran penerapan teknologi augmented reality pada keilmuan mata pelajaran yang dapat dipakai di sekolah.

\section{TINJAUAN PUSTAKA}

Beberapa pengabdian kepada masyarakat sebelumnya telah melakukan jenis pelatihan dengan bentuk pelatihan yang diterapkan pada pengabdian yang dilaksanakan, seperti pada pengabdian pertama yaitu yang dilaksanakan oleh (Hardianto, Fajrizal and Darmayunata, 2020) yang melaksanakan pelatihan penggunaan system informasi geografis lokasi lembaga swadaya masyarakagt di Kesbangpol Pekanbaru, dimana pada pengabdian ini dilaksanakan dengan cara memberika ceramah kepada masayarakat. Selama pelaksanaan pengabdian, ceramah dilakukan dengan cara memberikan panduan secara berurutan mengenai mekanisme penggunaan dari aplikasi yang telah dikembangkan. Pengabdian masyarakat berikutnya yang dilaksanakan oleh (Zamsuri, Syafitri and Febriadi, 2020), dimana bentuk pelaksanaan pengabdian kepada masyarakat dilakukan dalam bentuk workshop atau praktikum dengan tema pembuatan desain konten dan sosialisasi organisasi masyarkat. Pola praktikum dibutuhkan sebagai pembelajaran mandiri dari peserta pengabdian. Berdasarkan pola pengabdian kepada masyakarakat yang pernah dilakukan oleh pengabdian sebelumnya, maka pada pengabdian masyarakat yang dilaksabakan di sini menggunakan konep ceramah, praktikum dan evaluasi. 


\section{METODE PELAKSANAAN}

Pengabdian kepada masyarakat yang telah dilaksanakan, dilakukan dengan metode ceramah, metode praktikum dan evaluasi sesuai dengan kebutuhan dari peserta kegiatan pelatihan dan memastikan bahwa para peserta dapat memahami dan mampu membangun aplikasi augmented reality secara sederahana. Metode ceramah digunakan sebagai pendekatan dalam penyampaiann bahan ajar yang sesuai kepada peserta pelatihan. Pada dasarnya penggunaan metode ceramah hanya dapat dilakukan untuk sebagai pembuka dari kegiatan pelatihan serta menjelaskan materi dasar kepada para peserta pelatihan yang masih awam terhadap topik atau tema dari perlatihan augmented reality. Adapun susunan materi yang diberikan dengan metode ceramah adalah seperti :

1. Pengenalan secara umum tentang Augmented Reality

2. Sejarah Perkembangan Augmented Reality

3. Potensi Pengembangan Augmented Reality sebagai Alat Peraga

Namun metode ceramah tidak cocok diterapkan pada seluruh sesi pelatihan dikarenakan pelajaran berjalan cenderung membosankan karena peserta tidak diberi kesempatan untuk menemukan sendiri konsep yang diajarkan, peserta menjadi pasih hanya aktif membuat catatan saja, dan kepadatan konsep-konsep yang diajarkan dapat berakibat para peserta tidak mampu menguasai bahan yang diajarkan, untuk itu dibutuhukan metode lainnya untuk menunjang kemampuan teknis dari para peserta pelatihan, yaitu pelatihan bertahap atau disebut metode praktikum.

Menurut (Pratiwi and Wasis, 2013) memberi pengertian bahwa metode praktikum adalah proses pembelajaran dimana peserta didik melakukan pembelajaran dengan mengalami sendiri, mengikuti proses, mengamati obyek, menganalisis, membuktikan dan menarik kesimpulan suatu obyek seperti yang dapat dilihat pada gambar 1.

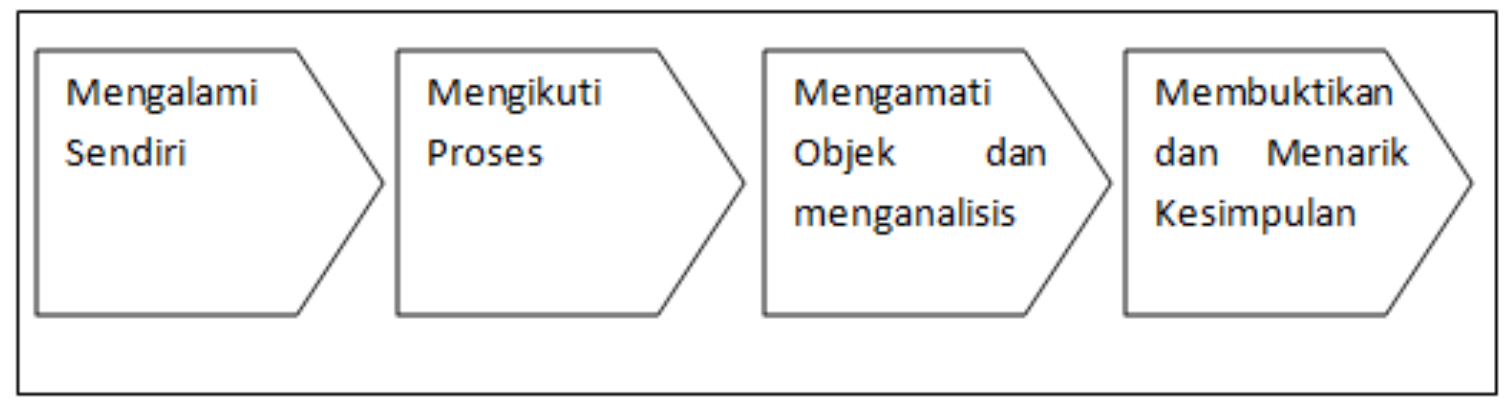

Gambar 1. Metode Praktikum

Adapun susunan materi dari pelaksanaan praktikum yaitu :

1. Pengenalan Unity sebagai platform pengembangan

2. Pengenalan Vuforia SDK sebagai SDK augmented reality

3. Pengenalan tool dasar aplikasi unity

4. Pemembuatan scene di unity

5. Bagaimana mengubah material di unity

6. Bekerja dengan kanvas di unity

7. Membuat marker di vuforia

8. Setting unity untuk augmented reality

9. Membuat alat Peraga Hidrologi 
Metode terakhir yang diterapkan pada pelatihan ini adalah evaluasi, dimana evaluasi diperlukan untuk memastikan bahwa peserta pelatihan dapat memahami dan mampu menjalankan instruksi yang telah diberikan pada saat praktikum. Metode ini penting dilakuakan sebagai umpan balik yang diberikan dari peserta kepada pelaksana pengabdian.

\section{HASIL DAN PEMBAHASAN}

Pengabdian kepada masyarakat yang diselenggarakan dalam bentuk pelatihan selama sehari ini dilaksanakan oleh satu dosen Program Studi Teknik Informatika yaitu Bapak Budi Arifitama berdasarkan undangan yang diberikan oleh asosisasi APSI. Kegiatan pengabdian ini dimulai dengan ceramah oleh narasumber seperti pada gambar 2 .

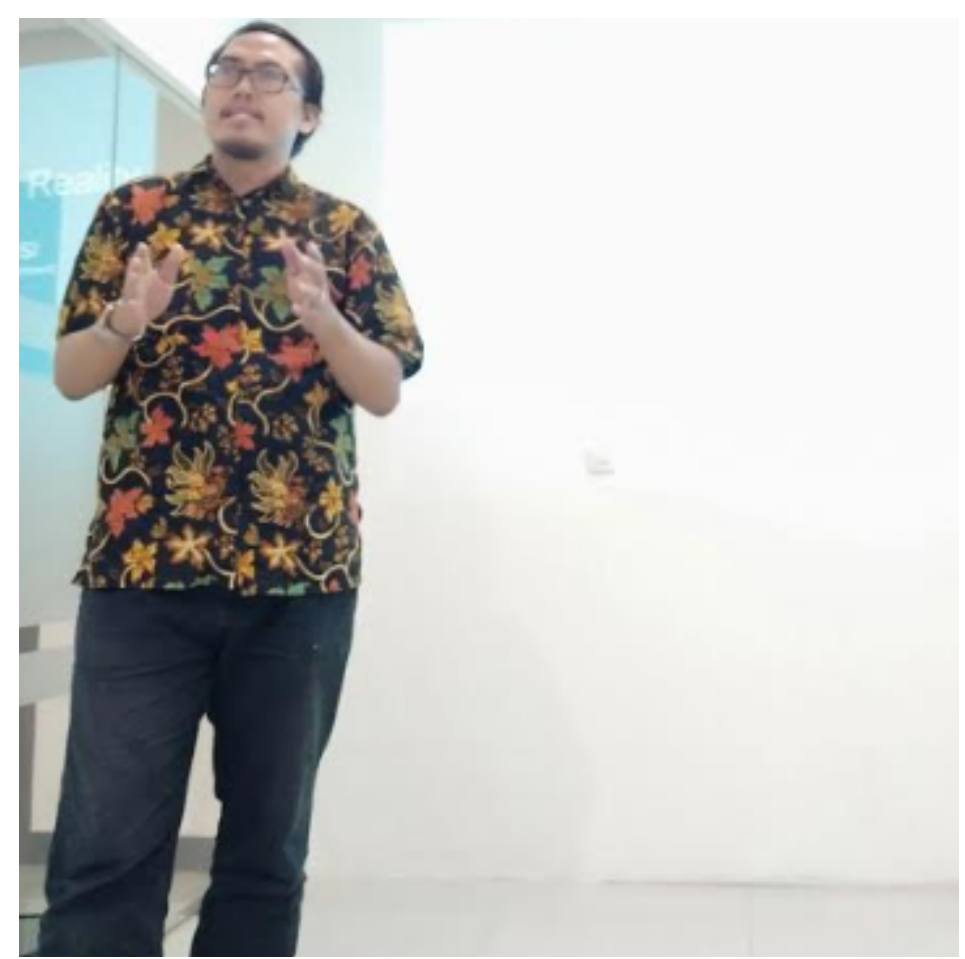

Gambar 2. Ceramah Pada Sesi Pembuka

Pada gambar 2, narasumber sedang melakukan kegiatan ceramah didepan para peserta pelatihan, dimana tema yang dijelaskan adalah mengenai penjelasan umum mengenai teknologi augmented reality, dimana teknologi augmented reality di Indonesia sendiri telah hadir semenjak pada awal tahun 2012, dimana teknologi ini memberikan inovasi yang dapat dipakai di dunia pendidikan, untuk memberikan visualisasi benda atau alat peraga yang digunakan dalam proses pembelajaran. Pelatihan ini dikhususkan untuk memberikan keterampilan dasar kepada para peserta untuk membuat augmented reality yang nantinya dapat digunakan dalam proses pembelajaran di kelas. Setelah selesai dengan kegiatan ceramah, maka dilanjutkan dengan kegiatan selanjutnya adalah dengan pelaksanaan praktikum yang dapat dilihat pada gambar 3 . 


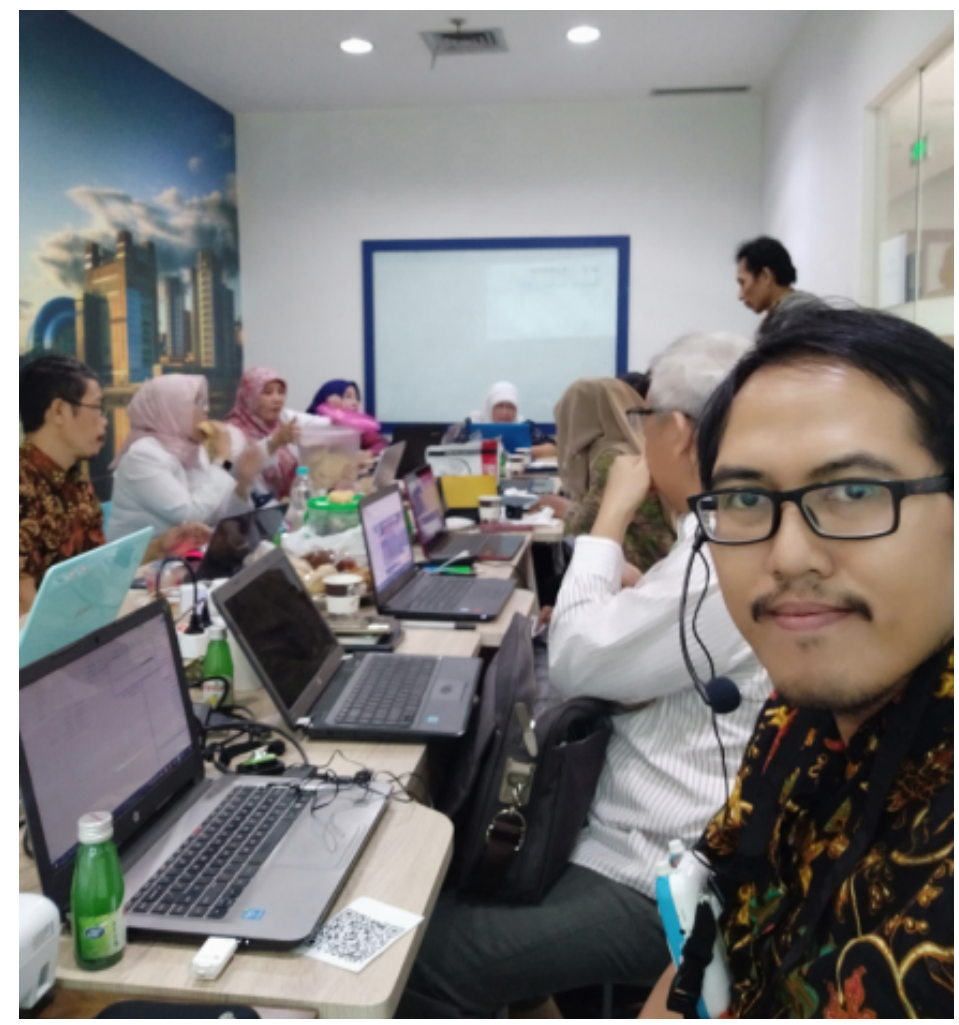

Gambar 3. Pelaksanaan Praktikum

Gambar 3 merupakan gambar proses pelaksanaan praktikum, dimana narasumber mendemonstrasikan tahapan-tahapan dari pembuatan sebuah objek augmented reality. Pada sesi ini penjelasan augmented reality dilakukan dengan cara bertahap mengenai pembuatan aplikasi hidrologi berbasis augmented reality. Beberapa kegiatan dalam pembentukan tahapan hidrologi dapat dilihat pada gambar 4. Gambar 4 merupakan tahapan pembentukan landscape dasar dari area perumahan dan lingkungan sekitar seperti pegunungan dan pepohonnan, pembuatan landscape pada pelatihan ini memanfaatkan platform Unity sebagai platform pengembangan.

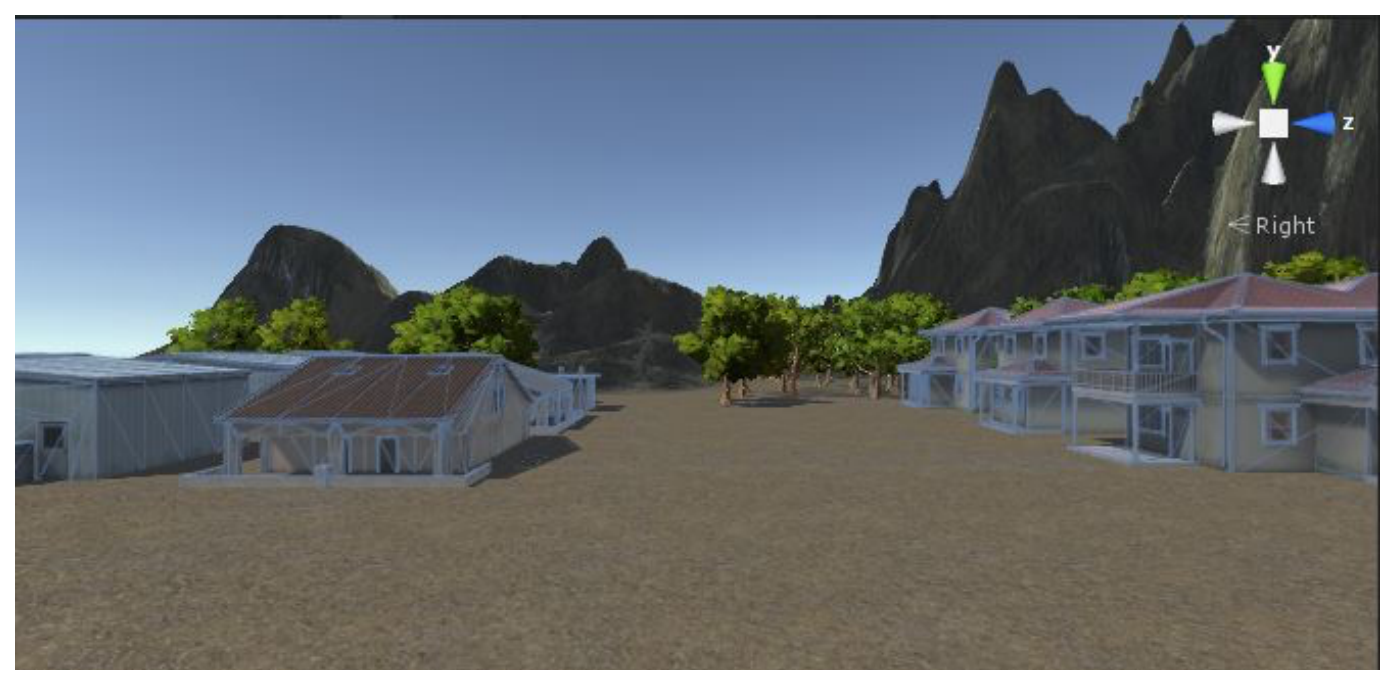

Gambar 4. Pembuatan Landscape Kota 


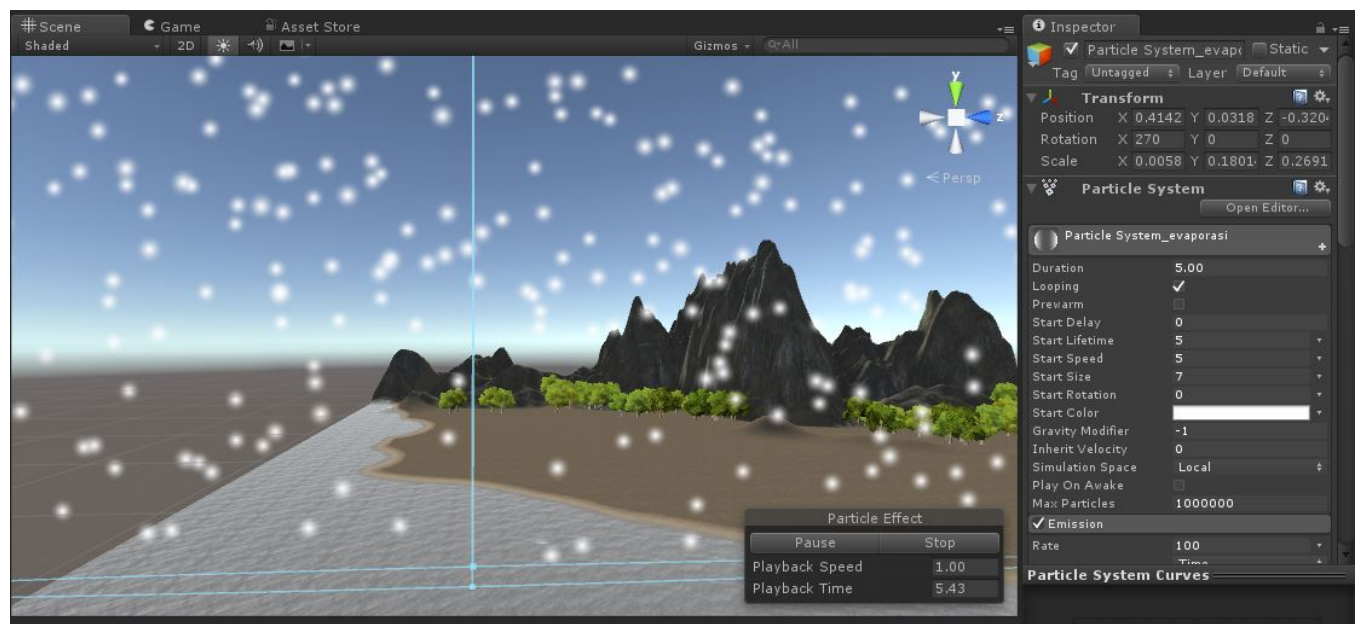

Gambar 5. Pembuatan Partikel Hujan

Gambar 5 merupakan gambar pembentukan partikel hujan, dimana dasar komponen partikel jika dijalankan akan tidak beraturan, pada konfigurasi partikel ditambahkan komponen gravitasi agar partikel terebut seolah-olah turun bagaikan hujan.

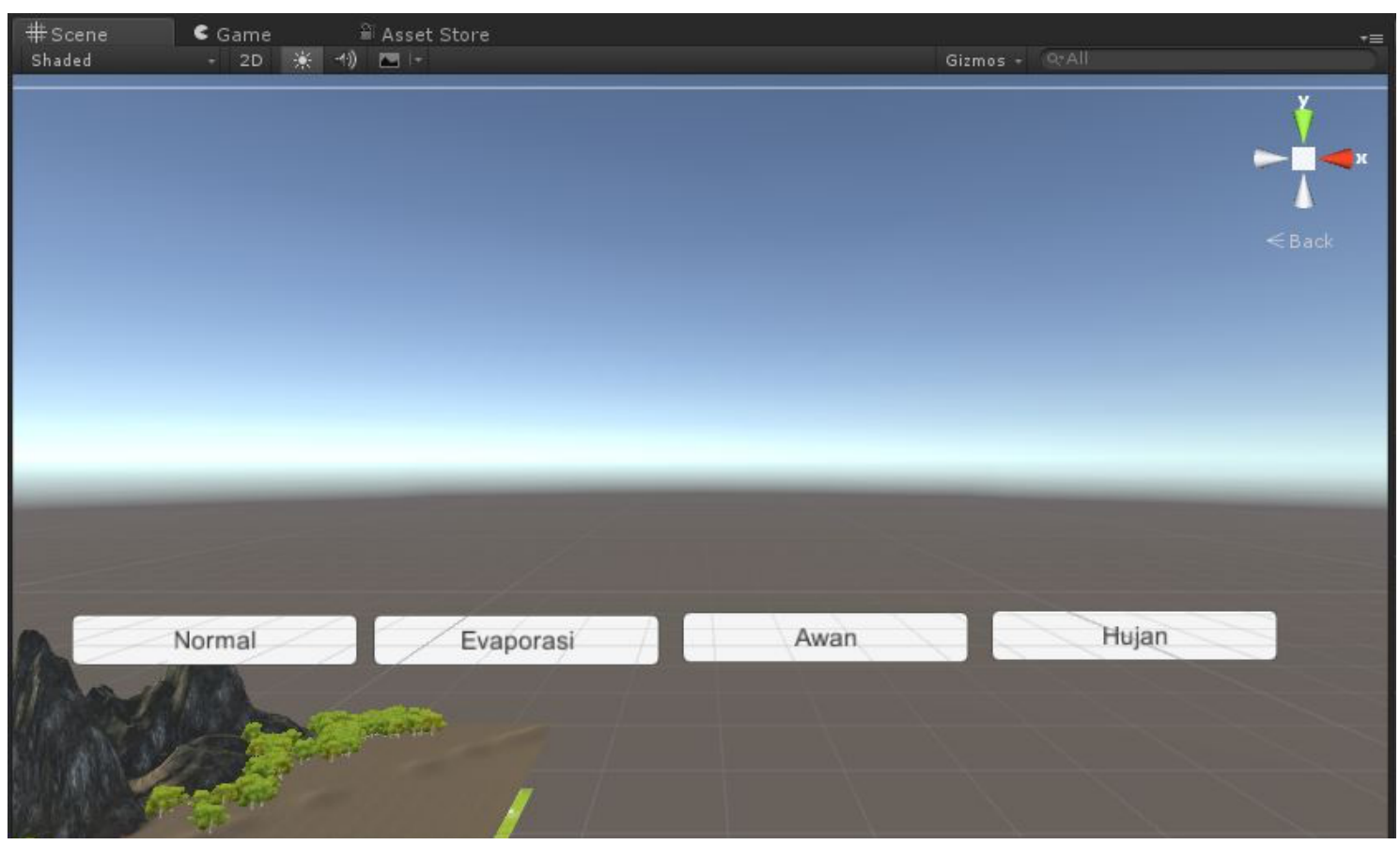

Gambar 6. Pembuatan Tombol Proses Hidrologi

Gambar 6 merupakan gambar pembuatan menu dari aplikasi hidrologi berbasis augmented reality, dimana pengguna akan menekan tombol tersebut sesuai dengan urutan terjadinya proses hidrologi, dimulai dari keadaan normal, evaporasi, hujan dan terakhir adalah hujan. 


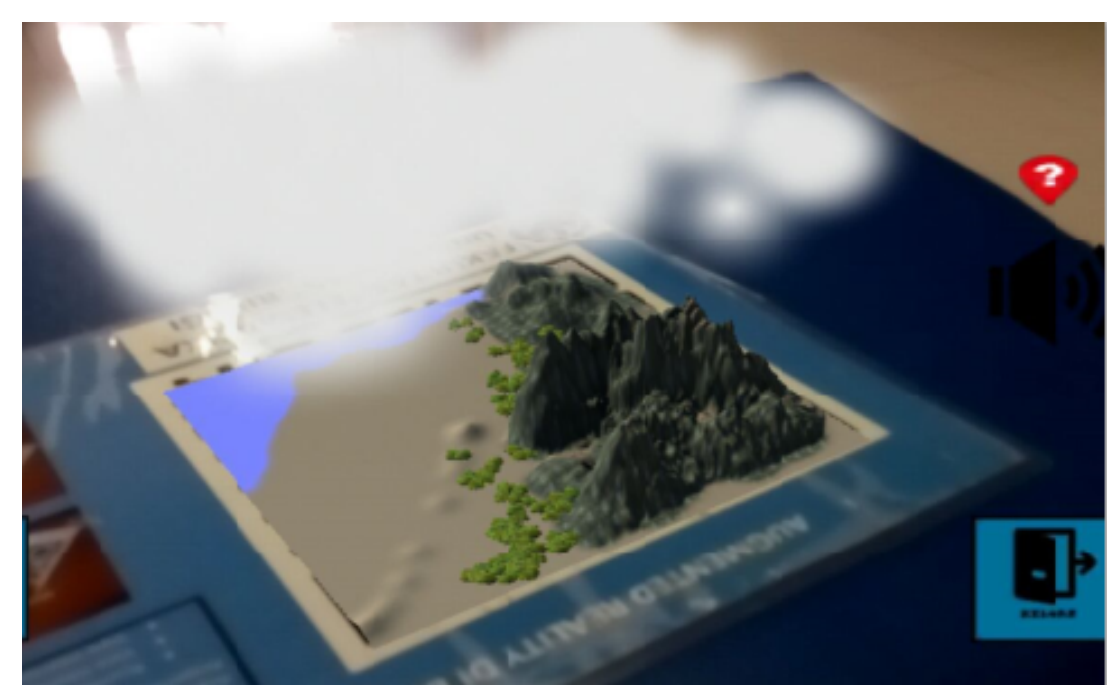

Gambar 7. Proses Pembentukan Awan Augmented Reality

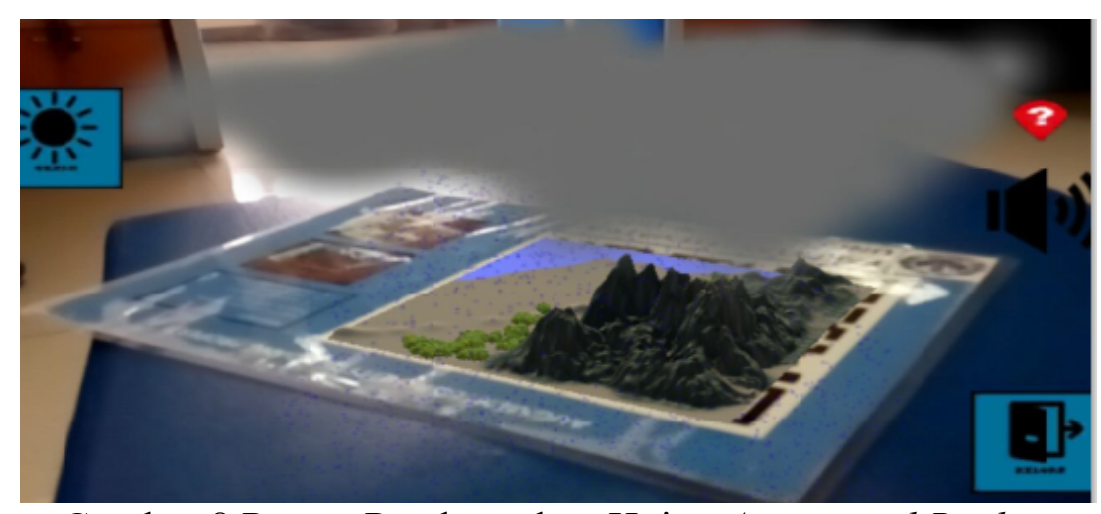

Gambar 8.Proses Pembentukan Hujan Augmented Reality

Gambar 7 dan 8 merupakan hasil dari aplikasi hidrologi berbasis augmented reality yang merupakan proses pembentukan awan yang berhujung pada simulasi air hujan yang turun dari awan. Setelah dilaksanakan kegiatan praktikum, maka akhir dari kegiatam ini adalah evaluasi para peserta dimana kegiatan evaluasi ini dilakukan dengan cara melihat apakah para peserta mampu mengerjakan semua instruksi selama pelatihan, dan hasil dari evaluasi bahwa seluruh peserta dapat membuat aplikasi augmented reality dengan baik.

\section{KESIMPULAN}

Pelaksanaan pengabdian masyarakat dengan tema pelatihan pembuatan aplikasi alat peraga berbasis augmented reality berhasil dilaksanakan dan seluruh peserta dapat membangun aplikasi augmented reality berdasarkan tuntunan dari pelatih. Hasil dari pengabdian ini dapat bermanfaat untuk para guru sebagai bahan pengayaan pembelajaran. 


\section{DAFTAR PUSTAKA}

[1]. Arifitama, B. (2015) 'Pengembangan Alat Peraga Pengenalan Tata Surya Bima Sakti Menggunakan Augmented Reality di PAUD’, Jurnal SISFO, 5(4), pp. 446-453.

[2]. Azuma, R. T. (2017) 'Making Augmented Reality a Reality', in Imaging and Applied Optics 2017 (3D, AIO, COSI, IS, MATH, pcAOP), p. JTu1F.1. doi: 10.1364/3D.2017.JTu1F.1.

[3]. Hardianto, R., Fajrizal, F. and Darmayunata, Y. (2020) 'Pelatihan Menggunakan Sistem Informasi Geografis Lokasi Lembaga Swadaya Masyarakat Di Kesbangpol Pekanbaru', Jurnal Pengabdian Masyarakat Multidisiplin, 4(1), pp. $1-8$.

[4]. Pratiwi, A. and Wasis, - (2013) 'Pembelajaran dengan Praktikum Sederhana Untuk Mereduksi Miskonsepsi Siswa Pada Materi Fluida Statis di Kelas XI SMA Negeri 2 Tuban', Inovasi Pendidikan Fisika.

[5]. Syahputra, A. and Arifitama, B. (2018) 'Pengembangan Alat Peraga Edukasi Proses Siklus Air (Hidrologi) Menggunakan Teknologi Augmented Reality', in Seminar Nasional Teknologi dan Multimedia (SEMNASTEKNOMEDIA), pp. 2$11-1$.

[6]. Zamsuri, A., Syafitri, W. and Febriadi, B. (2020) 'Desain Konten Promosi Dan Sosialisasi Organisasi Masyarakat', Jurnal Pengabdian Masyarakat $M$ ultidisiplin, 4(1), pp. 40-47. 